\title{
Elementary Introduction of Way of Localization of Composite Sliding Bearing for Hydroelectric Engineering
}

\author{
Li Yunlong \\ Dalian Sanhuan Composite Material Technology Development Co., Ltd., Dalian, China
}

Email address:

lyl@dlsh.cn

\section{To cite this article:}

Li Yunlong. Elementary Introduction of Way of Localization of Composite Sliding Bearing for Hydroelectric Engineering. Journal of Water Resources and Ocean Science. Vol. 7, No. 3, 2018, pp. 55-59. doi: 10.11648/j.wros.20180703.15

Received: August 26, 2018; Accepted: September 14, 2018; Published: October 22, 2018

\begin{abstract}
This article describes the process of replacing imported bearings with domestic composite sliding bearings in the hydroelectric engineering industry from three main aspects: thrust bearing of hydraulic generator, water distributor bearing of hydraulic turbine and spherical plain bearing of steel gate of hydraulic metal structure; expounds that we have adopted the development mode of imitation and independent innovation instead of plagiarism or re-innovation after technology introduction. In the process of domestic development, we relied on our continuous learning and innovation, focused on intellectual property protection, and aimed at the advanced international level; summarizes the achievements made in the application technology level of domestic products through our own efforts over the past 40 years, i.e. achieving the replacement of imported bearings with domestic bearings and realizing the export of domestic bearings; and presents the prospect of application of composite sliding bearings in hydroelectric engineering.
\end{abstract}

Keywords: Composite Sliding Bearing, Hydroelectric Engineering, Domestic Bearing

\section{Overview}

Sliding bearings are classified into unlubricated bearing, boundary lubricated bearing and fluid lubricated bearing based on lubricated conditions. With their more varieties and different characteristics, sliding bearings are widely used. Traditional sliding bearings are only made of cast iron, copper alloy, babbitt metal, nylon, birchwood, etc. With the development of science and technology, especially the progress of materials science and technology, composite bearing has become the mainstream variety of sliding bearing. Since the invention of the DU and DX composite bearings by British GLACIER Company in the 1960s and the development of the elastic metallic-plastic pad by former Soviet Union in the 1970s, countries all over the world followed to produce these novel products. After more than 40 years of innovation and development, the domestic composite sliding bearing industry has derived various types which were fully developed in material, variety, series, batch, etc. The method of lubrication has developed into boundary lubrication and oil-free lubrication (i.e., self-lubrication) instead of single oil lubrication. And its application field has also been expanded unprecedentedly, including hydroelectricity, automobile, tractor, transport machinery, heavy machinery, engineering machinery, textile machinery, mining machinery, household appliance, aerospace, etc.

The domestic composite sliding bearings have been applied in the water conservancy industry for more than 40 years, and the main application fields are shown in the table below:

Table 1. List of Main Application field of Composite Sliding Bearings in Hydroelectric Engineering Industry.

\begin{tabular}{|c|c|c|c|}
\hline Catalogue & Machine & Bearing name & Main Products applied \\
\hline $\begin{array}{l}\text { Hydroelectric } \\
\text { Generating }\end{array}$ & $\begin{array}{l}\text { Vertical } \\
\text { Hydrogenerator }\end{array}$ & $\begin{array}{l}\text { Thrust Bearing } \\
\text { Upper Guide Bearing } \\
\text { Lower Guide Bearing } \\
\text { Turbine Guide Bearing }\end{array}$ & Elastic Metallic-Plastic Pad \\
\hline Set & Vertical Turbine & $\begin{array}{l}\text { Guide Vane Bushing } \\
\text { Control Ring Wearing Plate }\end{array}$ & $\begin{array}{l}\text { Bimetal Self-lubricating Bearing, Copper Alloy Inlaid } \\
\text { Self-lubricating Bearing, and Polyformaldehyde Steel Backing }\end{array}$ \\
\hline
\end{tabular}




\begin{tabular}{|c|c|c|c|}
\hline Catalogue & Machine & Bearing name & Main Products applied \\
\hline \multirow{11}{*}{$\begin{array}{l}\text { Hydraulic } \\
\text { Metal } \\
\text { Structure }\end{array}$} & \multirow{3}{*}{$\begin{array}{l}\text { Horizontal } \\
\text { Hydrogenerator }\end{array}$} & $\begin{array}{l}\text { Servomotor Bushing } \\
\text { Runner Blade Bushing }\end{array}$ & Composite Bushing \\
\hline & & $\begin{array}{l}\text { Pedestal Bearing (including thrust bearing and } \\
\text { split radial bearing) }\end{array}$ & \multirow[b]{2}{*}{ Copper Alloy Inlaid Self-lubricating Spherical Bearing } \\
\hline & & $\begin{array}{l}\text { Tubular Turbine Guide Vane Spherical Plain } \\
\text { Bearing }\end{array}$ & \\
\hline & Arc Gate & $\begin{array}{l}\text { Hinge Spherical Plain Bearing } \\
\text { Hinge Bushing }\end{array}$ & \multirow{4}{*}{$\begin{array}{l}\text { Copper Alloy (Bimetal) Inlaid Self-lubricating Spherical Bearing } \\
\text { Copper Alloy (Bimetal) Inlaid Self-lubricating Bushing } \\
\text { Copper Alloy (Bimetal) Inlaid Self-lubricating Bushing } \\
\text { Copper Alloy (Bimetal) Inlaid Self-lubricating Spherical Bearing } \\
\text { Copper Alloy (Bimetal) Inlaid Self-lubricating Spherical Bearing } \\
\text { Steel Base Polyformaldehyde Slide, Bimetal Inlaid Self-lubricating } \\
\text { Slide and MC Nylon Slide }\end{array}$} \\
\hline & \multirow{3}{*}{ Plain Gate } & Fixed-Wheel Bushing & \\
\hline & & $\begin{array}{l}\text { Fixed-Wheel Spherical Plain Bearing } \\
\text { Side-Wheel Bearing }\end{array}$ & \\
\hline & & Support Slide & \\
\hline & \multirow{2}{*}{ Miter Gate } & Trunnion Bushing & $\begin{array}{l}\text { Copper Alloy Inlaid Self-lubricating Bushing and Bimetal } \\
\text { Self-lubricating Bushing }\end{array}$ \\
\hline & & Pintle Bearing Nest Ball Liner & $\begin{array}{l}\text { Copper Alloy Inlaid Self-lubricating Spherical Bearing (Mushroom } \\
\text { Head) }\end{array}$ \\
\hline & Turnover Door & Bottom Shaft Bearing & Engineering Plastic Alloy Spherical Bearing \\
\hline & Hydraulic Hoist & Rod End Spherical Plain Bearing & Copper Alloy (Bimetal) Inlaid Self-lubricating Spherical Bearing \\
\hline
\end{tabular}

\section{Process of Replacing Imported Bearings with Domestic Composite Sliding Bearings in Hydroelectric Engineering Industry}

The process of replacing imported bearings with domestic composite sliding bearings in the hydroelectric engineering industry is described below from three main aspects: thrust bearing of hydraulic generator, water distributor bearing of hydraulic turbine and spherical plain bearing of steel gate of hydraulic metal structure.

\subsection{Thrust Bearing of Hydraulic Generator}

Thrust bearing is a primary structural component of the hydropower generating unit, and its operation performance directly affects the reliability of the generating unit. With the continuous enlargement in unit capacity, the thrust bearing's load becomes larger and larger. The statistics of the operation conditions of hydraulic generator indicated that the accident rate of thrust bearings accounted for a large proportion of all accidents, approximately $70 \%$. To solve this problem, elastic metallic-plastic pad was invented by Kuybyshev Aviation Institute of former Soviet Union in the 1970s and firstly applied in Volga River Hydropower Station. More than 20 years of operation experience showed that the accident rate of thrust bearings has been decreased by $30 \%$. Since 1989, China successively imported elastic metallic-plastic pads (plastic pads) from former Soviet Union. The first batch was tried to use in hydropower stations including Longyangxia, Danjiangkou and Gezhouba, and obtained a good result. From early 1990, China began to develop this kind of composite pads and successfully put into trial use in Chuanchangxi Hydropower Station in Fujian province. After that, this kind of pads had been applied in Shimen and Xinanjiang Hydropower Station later on, which opened the localization era of plastic pads. Since then, domestic plastic pads have been applied safely for 28 years in large and medium-sized hydroelectric generating sets in China [2].

During the localization process of elastic metallic-plastic pads, China owned completely independent intellectual property right due to technology secret, and did not take a technology introduction mode. Localization is innovation based on imitation, which is mainly reflected in the following two aspects: (1)ingredient of surface friction layer: Russian plastic pad uses pure PTFE, while the surface material of the domestic plastic pad uses filled PTFE with which the wear resistance is improved but without loss of friction performance; (2)compound technology of plastic layer and copper wire interlayer: Russian pad uses the technology of prefabricating PTFE into sheets and then laminating the sheets onto copper wire interlayer. while domestic pad uses an integrated molding method by inlaying resin powder onto copper wire interlayer and then pressing them together, so that the binding strength of the plastic layer and the copper wire interlayer is more reliable, thus avoiding delamination [4].

In 2003, investigation on the operation of 10 domestic power stations which use plastic pads was conducted, including Dongfeng in Guizhou province, Daxia in Gansu province, Gutianxi in Fujian province, Hongmen in Jiangxi province, Huanren in Liaoning province, Qingtongxia in Gansu province, Xijiang in Zhejiang province, Xiaoshan and Yanguoxia in Gansu province. Among these power stations, the longest operating time was over 32,000 hours. Dongfeng station, which has the largest capacity $(170 \mathrm{MW})$ per unit, had been also operated for 3000 hours. The unit belong to variable load type, and its startup and shutdown cycles were more than 300 times each year. The investigation results indicated that the operation of plastic pads at these power stations was very satisfactory: the pads' temperature were normal (about $40^{\circ} \mathrm{C}$ generally), could be installed without Scratching beforehand, were capable of warm start and overwork, did not need high pressure oil jacking devices, had no damage to rotating plate, and operated reliably.

In July 2011, China Yangtze Power Co., Ltd. Overhaul \& Maintenance Factory carried out an inspection on one plastic 
pad (sampling quantity: 1 piece) of No.4 generator of Gezhouba Hydropower Plant. The plastic pad had a total wear value of $0.15 \mathrm{~mm}$ after 16 years operation since 1995, and all of the other technological characteristics were normal. Therefore, the plastic pad was reinstalled for continued use.

In 2008, in order to meet the requirements of lead-free products in domestic and international markets, a new generation of plastic pads were developed successfully, which not only met national environmental protection requirements, but also improved wear resistance by more than 100 times. In 2009 , this kind of plastic pads were applied to the Goupitan generating unit of $600 \mathrm{MW}$. During the overhaul inspection of No.1 generating unit in February 2011, it was observed that the pad surfaces were in good condition with only slight abrasion marks. The generating unit had experienced an accumulated operating time of 15,438.8 hours and 1,039 cycles of startup and shutdown within the past 2 years. The maximum average annual wear value was only $0.06 \mathrm{~mm}$. It was predicted that the lifetime of the plastic pads could be more than 30 years [9].

In 2011, the experimental research of plastic pads on $1000 \mathrm{MW}$ generating unit was successfully completed. The new generation of elastic metallic-plastic pads was then applied to No.3 hydropower generating unit of $770 \mathrm{MW}$ in Xiluodu Hydropower Station in 2014, and has been operated at full load for more than 4 years until now. Its temperature remains at about $46^{\circ} \mathrm{C}$, and the temperature difference between pads is about $2.4^{\circ} \mathrm{C}[10]$.

Since 2009, China-made plastic pads have been exported to Russia, Canada, Finland, Norway, India, Vietnam, Indonesia, Austria and other countries. In particular in 2013, 4 batch of plastic pads for generating units of SMOKY FALLS project of Canadian(made by ALSTOM )passed the acceptance inspection succesfully, indicating that the China-made bearings not only won international recognition in technology, but also made a qualitative leap in quality management. From import to export, China-made plastic pads achieved a magnificent turnaround.

\subsection{Hydro-turbine Distributor Bearing}

Numerous sliding bearings are installed in hydro-turbines and their auxiliary devices, including upper, middle and lower bushings of guide vanes, connecting rod pin bushings, regulating ring sliding plates, butterfly valve shaft bushings, etc. Operating in high load and low speed conditions, all of these bearings are susceptible to boundary lubrication or dry friction even if grease lubrication or oil lubrication is provided, and therefore, the bushing must be made of self-lubricating material. Before 1960s, the traditional bearings of all countries were generally made of high quality tin bronze. With the extensive use of engineering plastics in machinery manufacturing industry, the tin bronze was replaced by nonmetal material, such as Soviet birchwood bearing. Although the birchwood bearing has the disadvantages of complicated fabrication process and water swelling, the trouble of drilling deep oil-feeding holes in the guide vane stem was solved. A new kind of guide vane bushing and connecting rod pin bushing with PTFE solid lubricant embedded in high-strength copper alloy was studied in Japan. The guide vane bushing and connecting rod pin bushing were applied to the 60MW hydraulic turbine of New Narude Hydropower Station in 1976 after 60,000 times of laboratory swing tests. Furthermore, the guide vane bushing manufactured by French Neyrpic for the hydraulic turbine of Fuchun River Hydroelectric Power Station was a copper bushing with internal PTFE plate, while the hydraulic turbine of China's Bapanxia Hydropower Station manufactured by Sweden KMW still used tin bronze guide vane bushing [1]. In 1990s, DEVA-BM and DEVA-GLIDE products of Germen DEVA, 500\# of Japanese OILES and Sweden ORKOT were introduced into China. DEVA-BM is a bimetal self-lubricating bearing material that takes a steel plate as the backing and takes sintered bronze powder as the frictional surface layer with solid lubricants uniformly distributed in it. DEVA-GLIDE and OILES500\# are materials of copper alloy inlaid with solid lubricants. ORKOT ${ }^{\circledR} \& d e c$ material is a composite material of fine woven fiber impregnated with special thermosetting polyester resin [8].

Turbines designed and produced in China had replaced the tin bronze bushing with self-lubricating engineering plastics ones since the 1960s, which not only omitted the maintenance work of regular point-by-point oil supply of power station, but also eliminated the pollution of lubricating oil to rivers, and was particularly welcomed by power-stations. However, journal sticking due to water swelling occurred during the operation by early used MC nylon bushings, because that the MC nylon bushing was not tested before use, and the material's properties were not fully grasped. Subsequently, Polyformaldehyde bushings with low water absorption manufactured by means of die forming was used. In the 1970s, a study on Polyformaldehyde steel backing composite material (equivalent to DX of GALACIER, which is called GS-2 and FZB02 in China) was conducted in China. This composite material was first applied in Liuxihe Power Station in Guangdong province and obtained a successful result in early 1980 s, and then was widely promoted and used. In the 1990s, a study on copper alloy inlaid self-lubricating bearing and bimetal self-lubricating bearing was conducted.

The copper alloy inlaid self-lubricating bearing takes high quality copper alloy as base material to bear working load, and specified quantity of cavities are distributed as designed in the copper alloy bases and solid lubricants are filled into the cavities to provide the bearing with self-lubricating property. The properties of the solid lubricants decide the performance of the bearing. The solid lubricants shall have a small friction coefficient, excellent adhesion property and good expansion property. After ten years of unremitting study efforts, properties of solid lubricants have been improved. The results of comparison test showed that the friction coefficient and wear rate of the bearing with this solid lubricants can be compared to those of foreign products of the same kind.

Since its successful development in 1999, the bimetal self-lubricating material bearings (called DEVA-BM abroad and called FZB06 in China) had been used as guide vane 
bushings of many hydro- turbines, such as Wanjiazhai, Taipingyi, Mianhuatan, Longtan and other domestic hydraulic power stations. However, there is a certain gap between China-made bearings and advanced foreign products in terms of friction and wear properties, dimensional accuracy and appearance quality. In 2009, on the original basis, a high performance bimetal self-lubricating sliding bearing was successfully developed. Because the advanced powder metallurgy sintering technology was used, the content of solid lubricants in the copper alloy surface layer is made up to nearly $10 \%$, thus the loading capacity and wear resistance were also improved. The results of laboratory simulative comparison test in Shanghai University in China, ALSTOM in France, OILES in Japan showed that the dry friction coefficient, water-lubricating friction coefficient and wear rate were comparable to those of foreign products. After being subject to laboratory tests, the sliding bearing was applied to the hydro-turbine distributor of $600 \mathrm{MW}$ generating unit of Goupitan Hydropower Station[7], from then on, a way of replacing imported bearings with domestically produced ones is opening up.

\subsection{Self-lubricating Spherical Plain Bearing Used in Steel Gate of Hydraulic Metal Structure}

Self-lubricating spherical plain bearings have drawn much attention in the field of engineering due to its good performance, such as high loading capacity, low frictional resistance, long service life, the ability of carrying eccentric load, the ability of automatic rectifying deviation and strong adaptability [5]. At present, this kind of bearing is more and more widely used in hydraulic gates, such as plain gates, arc-gate and hydraulic hoists [3]. Before the 1990s, imported bearings dominated in the market of domestic water conservancy projects, especially in large and super-large ones. Representative foreign manufacturers are SKF, DEVA and INA.

SKF has three kinds of products, among which the self-lubricating material used by GEP...FS is glass fiber reinforced PTFE; the self-lubricating material used by GE...P4S is sintered bronze composite with solid lubricant uniformly distributed, and then the composite is embedded into circular holes of the annular surface. The above two products are applied to arc-gate hinges; SKF has introduced GE...TXA-2LS bearing that uses PTFE fabric as the self-lubricating material, and takes medium carbon steel or stainless steel as the matrix, and applied to hydraulic hoists. The main product of DEVA is copper alloy inlaid self-lubricating bearing (DEVAGLIDE) which is mainly applied to arc-gate hinges and plain gates. The main product of INA is PTFE fabric composite material which takes woven PTFE fibers as its frictional overlay and takes medium carbon steel or stainless steel as its matrix.

Since the application in Dachaoshan project in 1998, domestic self-lubricating spherical plain bearings have been applied to hydraulic metal structures for nearly 20 years. What is particularly worth mentioning is that the Three Gorges Project has adopted domestic GEW220XFZ5 and
GEW180XFZ5 spherical plain bearings as the fixed wheel bearings of the rapid gates in its underground power house. These bearings are used 140 meters depth under water, and the bearing pressure and underwater environmental conditions are very harsh. In order to ensure the safety of the project, running-in test was carried out simultaneously along with the life test of all the bearings on a multi-functional test machine of 400 tons ( pressure of $84 \mathrm{MPa}$, speed of $0.02 \mathrm{~m} / \mathrm{s}$, total slip distance of 2,000 $\mathrm{m}$ ) before the bearings leave the factory. The bearings were installed on the gates after being qualified and has been running well up to now [6].

Although imported bearings have been partially replaced by domestic ones in domestic water conservancy projects, imported bearings are still mostly used in large and super-large projects. Wanmipo Hydropower Station in Hunan province was the first to adopt domestic GEW530HFZ5 spherical plain bearings in 2003, which set a new record for domestic large self-lubricating spherical plain bearings. The domestic spherical plain bearings of 630 diameter were applied to Xihe Hydropower Station in 2005, and then domestic spherical plain bearings of $630 \mathrm{~mm}$ and greater diameters were successively applied in the hydropower stations such as Pengshui, Caojie, Bailianya, Xiluodu, Shuhe, Laokou and Gaobei, which gradually replaced the imported bearings in the water conservancy projects. The domestic bearings were not only used as substitutes for imported ones, but also exported to the countries such as Vietnam, Myanmar and Ethiopia to their numerous projects.

In view of the operation experience of self-lubricating spherical plain bearings made both at home and abroad in nearly two decades, through unremitting efforts and research, the following new technologies have been successfully developed for domestic bearings: (1) rust prevention technology: as a new technology, duplex stainless steel ring is used to be matched with the self-lubricating material ring, and the problem of rusting due to the fact of working in water or in humid atmospheric conditions has been completely solved; (2) the new technology of solid lubricant for inlaid bearings: aimed at the international advanced level, a new generation of solid lubricant has been developed independently, with which the antifriction ability, adhesion and expansibility improved very much; (3) online monitoring technology: the online monitoring technology of hinge spherical plain bearings for arc gates has been developed successfully and have been applied to Yongning project in Guangxi province, which is to judge whether the bearings are in normal operation or not by monitoring the sliding displacement between the inner and outer rings, and make comparison with the opening of the gate, the data is transmitted to the PLC control system of powerstation, and the remote wireless transmission is realized; (4) the new technology of bearing end cap sealing: sealing failure is a common failure mode for self-lubricating spherical plain bearings, which will result in water and silt infiltrating the bearing surface, and causes rusting and jamming. Therefore, a new special shape sealing structure of end cap developed, which effectively solves this problem. The breakthrough of the above core technologies makes domestic 
products more and more advance and reliable.

\section{Prospect}

By the end of 2014, the totally installed power-generating capacity had reached 1360,190 MW in China, of which $301,830 \mathrm{MW}$ was hydropower (including 21,830 MW of pump storage) and accounts for $22.2 \%$ of the installed gross capacity. According to the forecast of National Academy of Economic Strategy (NAES) of Chinese Academy of Social Sciences (CASS), the primary power demand will maintain a steady growth during the 12th and 13th Five-Year Plan Periods; the average annual growth is expected to be $6.7 \%-7 \%$. The development of hydropower industry will certainly drive the development of related supporting part and component industry. Creating high-efficient sliding bearing industry is in line with both the national industrial policy and the key parts component policy of water conservancy in China. In addition, the strategy of based-on-condition maintenance and smart grid construction has been determined, and online monitoring products have become an indispensable part of the strategy. Online monitoring technology refers to the measurement and diagnosis system which are directly installed on the machines and can record the characteristic quantity of the running state of the equipment in real time. An online monitoring system is generally composed of advanced sensor technology, computer and information processing technology, communication system, expert analysis system and relatively complete system database.

China is already among the big manufacturers of self-lubricating bearings in the world, but is not yet a strong manufacturer. Domestic manufacturers should always take technological innovation as the key development goals, invest a huge amount of money on the research and development activities of scientific and technological projects. Meanwhile, the bearing manufacturers should also foster a group of experienced scientific and technical personnel related to self-lubricating bearings and lay a firm foundation for the comprehensive substitution of Chinese self-lubricating bearings for imported ones and the subsequent long-term development of the industry in the future.

\section{Conclusion}

The research and development of domestic composite sliding bearings in water conservancy project industry has gone through a process of more than 40 years. The technical route is not through technology introduction or re-innovation after introduction, not plagiarism, but is from imitation to independent innovation relying on its own continuous learning. During R \& D process, manufactures in China pay much attention to intellectual property protection. As a result, not only the replacement of imported bearings with domestic bearings, but also the export of products realized. This is a correct way for China to transit from a big manufacturer to a strong manufacturer. Meanwhile, we should always keep in mind that the gap between domestic composite sliding bearings and imported bearings in some aspects, which requires constant effort to narrow the gap.

\section{References}

[1] Wang Minfu, Application of Polyformaldehyde Steel Backing Composite Material on Hydraulic Turbines [J] Large Electric Machine and Hydraulic Turbine, 1984(4); 53-61.

[2] $\mathrm{Qu}$ Shuzeng, Operation and Production of Elastic Metallic-Plastic Pads in China [J], Large Electric Machine and Hydraulic Turbine, 1992(5) 7-13.

[3] Zhang Leshi, Du Yeyan, Liang Changyu, Application of Self-lubricating Spherical Plain Bearing on Plain Fixed-Wheel Gate [J], Water Resources and Hydropower Engineering, 2000(5); 36-38

[4] Sun Chengyu, Nie Zhongde, et al., Reliability of Elastic Metallic-Plastic Thrust Pads for Application in Huge-Scale Hydroelectric Generator unit [J], Mechanical \& Electrical Technique of Hydropower Station, 2006, 29(3); 8-9.

[5] Yao Liang, On Optimum Design of Self-lubricating Spherical Plain Bearing in Hydraulic Steel Gates and Hoists [J], Zhihuai, 2006(9); 19.

[6] Ai Zhi, Chen Deping, Song Chao, Manufacturing Technology of Copper-Based Inlaid Self-lubricating Spherical Sliding Bearings [J], Machinery, 2010(12); 54-56.

[7] Lu Jun, Xu Gang, On Reliability of Guide Vane Bearings of 700 MW Hydraulic Turbine in Longtan Hydropower Station [J], Water Power, 2007(4); 44-45.

[8] Han Guiling, Optimization and Application of Guide Vane Bearings of Hydraulic Turbine [J], Power System Engineering, 2013(3); 63-65.

[9] Wang Guilai, Yi Jilin. Application of Domestic Elastic Metallic-Plastic Pads on 600 MW Hydropower Generating Unit [J]. Huadian Technology, 2014, 36(02): 8-12+78.

[10] Wu Siyuan, Application and Analysis of Elastic Metallic-Plastic Pad Thrust Bearings for Generator Sets of Xiluodu Hydropower Station [J], Hydropower and New Energy, 2017(2); 34-38. 